\title{
Correlations between pelagic distribution of Common and Brünnich's Guillemots and their prey in the Barents Sea
}

\author{
KJELL EINAR ERIKSTAD, TRULS MOUM AND WIM VADER
}

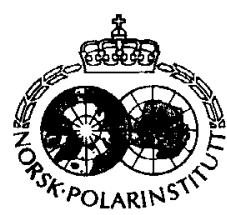

Erikstad, K. E., Moum, T. \& Vader, W. 1990: Correlations between pelagic distribution of Common and Brünnich's Guillemots and their prey in the Barents Sea. Polar Research 8, 77-87.

Correlations between guillemots (including Common Guillemots Uria aalge and Brünnich's Guillemots $U$. lomvia) and their prey (divided into five prey categories, capelin Mallotus villosus, herring Clupea harengus, polar cod Boreogadus saida, plankton, and a mixture of other prey species) at two depths (10-100 $\mathrm{m}$ and $100-200 \mathrm{~m}$ ) were estimated along an extended transect of 3,060 nautical miles $(5,667 \mathrm{~km})$ in the Barents Sea in April/May 1986. Spatial concordance was highest during daylight hours when the largest number of birds were seen on water (presumably feeding birds). Capelin was the single prey category which was most often associated with birds but no single prey category could alone explain the distribution of birds. Although only a small fraction of guillemots could be identified to species, there was some evidence that capelin were of greater importance to Common than to Brünnich's Guillemots. Overall correlation between birds and total prey density was statistically significant at the smallest scale of 5 nautical miles (n.m.). The removal of herring from the calculations increased the strength of the correlation. The depth at which prey was located had little effect on the distribution of birds. The correlation between birds and prey was scale dependent, and reached a maximum at $90 \mathrm{n} . \mathrm{m}$., although there seemed to be some upper threshold in the coefficient at c. $40 \mathrm{n} . \mathrm{m}$. Numerical concordance (including only $5 \mathrm{n}$.m. periods where both prey and birds were present) was significant at the $5 \mathrm{n}$.m. scale but was higher for high density than for low density prey patches. The results are discussed in relation to the few similar studies in other oceans and in relation to the severe reduction of important prey species in the Barents Sea.

Kjell Einar Erikstad, Norwegian Institute for Nature Research, Troms $\phi$ Museum, University of Troms $\phi, N$ 9000 Tromsø, Norway; Truls Moum and Wim Vader, Zoology and Marine Biological Departments, Troms $\varnothing$ Museum, University of Troms $\phi, N-9000$ Troms $\emptyset$, Norway; November 1989 (revised January 1990).

Feeding seabirds aggregate in large patches with chord lengths of several kilometres (Schneider \& Duffy 1985; Schneider \& Piatt 1986). One likely determinant of these aggregations is that food aggregates at a similar scale (Hunt \& Schneider 1987; Schneider \& Piatt 1986). Two main approaches have been applied to test the 'food aggregation hypothesis' (see Hunt \& Schneider 1987, Hunt this volume and Schneider this volume for reviews):

1. To look for correlations between aggregations of birds and the occurrence of fronts. This method is based on the observations that biological activity increases in areas of water mass boundaries (e.g. Pingree et al. 1975; Emery et al. 1973).

2. To directly correlate numbers of seabirds with the abundance of their prey (Obst 1985; Schneider \& Piatt 1986; Heinemann et al. 1989).

So far numerous studies have related pelagic seabird abundance to the physical properties of the ocean (see Hunt \& Schneider 1987 and
Schneider this volume for reviews), but only a few have correlated the distribution of birds with their prey (see Hunt \& Schneider 1987 and Hunt this volume for reviews). In general, the former show that birds aggregate at fronts, but that fronts explain only a very low fraction of the variance in avian abundance. The few studies of the relationships between seabirds and their prey have shown that the strength of correlation is highly variable (Hunt this volume) and that the correlation between birds and prey is stronger at large than at small scales (Schneider \& Piatt 1986; Heinemann et al. 1989). The relatively low variance of avian abundance explained by fronts may be, as pointed out by Schneider (this volume), due to the causal chain linking seabirds to fronts, namely that prey are linked to fronts whereas birds are linked to prey.

Spatial correlation of marine birds with prey is highly variable, with highest coefficients for larger spatial scales $(c .<10 \mathrm{~km})$ and for prey assemblages dominated by a single type of prey 
(Schneider \& Piatt 1986; Heinemann et al. 1989). The correlation with assemblages of several prey appears to be low in guillemots (Woodby 1984). However, Woodby (1984) did not look at correlation over several spatial scales.

This study analyses the correlation of guillemots with prey assemblages over a range of spatial scales. It also compares correlation of guillemots with individual prey species to correlation with the prey assemblage at the same spatial scale.

\section{Study area}

Observations were made from $\mathrm{R} / \mathrm{V}$ 'Eldjarn' in the Barents Sea from 29 April to 15 May 1986 along an extended transect of 3,060 nautical miles $(5,667 \mathrm{~km})$ in an area ranging from the Norwegian coast northward to the ice border at approximately $75^{\circ} \mathrm{N}$, and from west of Bjørnøya to west of Novaya Zemlya (Fig. 1).

The area is a shallow continental shelf with a mean depth of $230 \mathrm{~m}$ and few areas deeper than $400-500 \mathrm{~m}$ (e.g. Loeng 1989). There are three main water masses in the Barents Sea (e.g. Midttun 1985; Loeng 1989; Midttun this volume): the Norwegian coastal current and the Atlantic current which both flow into the Barents Sea from the southwest and the Arctic current system which brings arctic water in from the north. Where the Arctic and Atlantic water meet they mix and form the Polar front.

The Barents Sea is an important nursery and feeding area for several commercial fish species such as cod Gadus morhua, polar cod Boreogadus saida, haddock Melanogrammus aeglefinus, herring Clupea harengus, and capelin Mallotus villosus. Capelin is an important prey for both breeding and non-breeding guillemots in the area (Belopol'skii 1957; Furness \& Barrett 1985; Erikstad \& Vader 1989). During the non-breeding

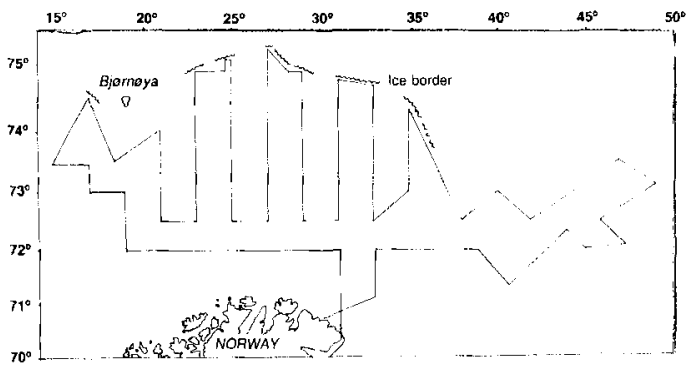

Fig. 1. Map of the study area showing the transect surveyed and the approximate position of the ice edge in April/May 1986. season, Brünnich's Guillemots also prey heavily on both gadoid fish and crustaceans (Erikstad in press).

\section{Material and methods}

\section{Bird observations}

Birds were counted from the top of the vessel's bridge $(10 \mathrm{~m}$ above sea level) in $300 \mathrm{~m}$ transects and $10 \mathrm{~min}$. blocks on one side of the ship (Tasker et al. 1984). The speed of the ship was about 10 knots, such that counts covered an area of about $0.92 \mathrm{~km}^{2}$ in $10 \mathrm{~min}$. The total number of $10 \mathrm{~min}$. blocks counted was 1,143 , covering an area of $1051.6 \mathrm{~km}^{2}$. Bird counts were made during the day, usually with a break between $2200-0200 \mathrm{hrs}$., and also with breaks when the boat was trawling.

No attempts were made to count the whole seabird community since some species, e.g. gulls, Fulmars Fulmarus glacialis, and Kittiwakes Rissa tridactyla were strongly affected by the trawling activity of the ship (Erikstad et al. 1988). We limited the observations to alcid species and bird counts followed the standard procedure suggested by Tasker et al. (1984). Flying birds were, however, counted continuously and not by dividing the $10 \mathrm{~min}$. transect into shorter sections. The procedure suggested by Tasker et al. (1984) minimises the problem of repeatedly counting birds circling around the ship. However, because flying alcids only cross the transects and are not affected by the presence of the ship, such effects could be disregarded. Bird numbers are probably underestimated since diving birds are not seen and some distant birds may be overlooked.

Common and Brünnich's Guillemots were difficult to separate at a distance, and only those seen close to the ship were identified to species.

\section{Estimates of prey densities}

The ship made quantitative acoustic/trawl survey estimates of the densities of different fish species in the area, according to standard methods. The instrumentation on board $\mathrm{R} / \mathrm{V}$ 'Eldjarn' included Simrad EK 400, a digital Scase echo-integrator and a Nord-10 computer for data storage and analysis, including echo-integration which aggregated data every 5 nautical miles (n.m.).

The echoes produce traces often characteristic for different prey species or prey categories. On 
this basis the integrator values were assigned to different prey categories. This procedure was verified by trawl net samples every $30-40 \mathrm{n} . \mathrm{m}$. or in areas of high integrator values. The prey categories were capelin, herring, polar cod, plankton and mixture. The last category groups together several fish species, the most numerous of which were cod, haddock and redfish Sebastes marinus $/ S$. mentella. The different prey categories were also assigned to two depth categories, $10-100 \mathrm{~m}$ and $100-200 \mathrm{~m}$.

\section{Data analysis}

Prey densities were measured to a minimum scale of $5 \mathrm{n} . \mathrm{m}$., whereas seabirds were counted in transects of $10 \mathrm{~min}$. blocks. To enable comparison of seabird and prey data at the minimum scale of 5 n.m., we used two methods. First, maps were drawn of prey and bird distributions, using a grid computer programme which could be varied in size from squares of $20 \times 20 \mathrm{~km}$ upwards. Secondly, to describe the patchiness and distribution of birds and prey along the continuous transect, we used the maximum number of birds seen within each 5 n.m. period as an index of bird density. Regressing total bird numbers against maximum numbers within $30 \mathrm{~min}$. periods (c. $5 \mathrm{n} . \mathrm{m}$. when the speed of the ship is 10 knots) showed that nearly all variation in avian density could be explained by this index $\left(\mathrm{r}^{2}=0.99\right)$.

The acoustic values of different prey species were used as an index of density only, since more information is needed for estimating absolute fish density (Johannesson \& Mitson 1983). The size distribution of different fish species is a very important factor in determining the suitability of prey to seabirds (Swennen \& Duiven 1977; Hulsman 1981).

We used a logarithmic scale in the presentation of data and in several analyses we also ranked the data in order to meet the assumptions of the statistical tests.

\section{Spatial scaling}

To examine the importance of spatial scale on the correlation between seabird density and prey density we analysed the seabird and prey density estimates from the $5 \mathrm{n} . \mathrm{m}$. periods and then the mean densities were calculated for larger scales by aggregating data over an increasing number of 5 n.m. periods $(2-20)$.
The day time counts of birds provided sampling units separated both in space and time. We used all segments longer than $10 \times 5 \mathrm{n} . \mathrm{m}$. periods (a total of 17 segments, covering a range from 10 to $27 \times 5$ n.m. periods), and tested for correlation between mean prey and bird density.

\section{Statistical testing}

The spatial association between guillemots and prey (defined as the degree to which seabird and prey present are related) was calculated at the $5 \mathrm{n} . \mathrm{m}$. scale. We tested the presence/absence data, and tested for differences in spatial associations at different times of the day ( $4 \mathrm{~h}$ blocks), using chi-square tests.

To estimate the overall correlation between seabirds and prey, we calculated Spearman rank correlations. The data could not be described by standard statistical models (see also Schneider \& Piatt 1986; Heinemann et al. 1989), so randomization tests were used to evaluate statistical significance. Correlation between seabirds and prey at the $5 \mathrm{n} . \mathrm{m}$. scale was tested for significance by comparing the observed correlation at this scale, $r(5)$ to one hundred values of the same statistic obtained by randomizing $5 \mathrm{n}$.m. prey data with respect to location. A Turbo-Pascal random generator was used to obtain random permutation of prey data. Bird data were not randomized in this test.

We tested the two following hypotheses (see also Schneider \& Piatt 1986): 1) the null hypothesis, $\mathrm{H}_{0}: \mathrm{r}(5)=0$, was rejected if an observed value of $r(5)$ was greater than 95 of 100 values of $r(5)$ from randomization data, and 2) the null hypothesis (scale independent correlation), $\mathrm{H}_{0}: \mathrm{r}(5)=\mathrm{r}(\mathrm{F})$, was rejected in favour of the alternative hypothesis, $\mathrm{H}_{\mathrm{A}}: \mathrm{r}(5)<\mathrm{r}(\mathrm{F})$, if 95 of 100 randomized values of $r(F)$ were greater than the observed $r(5)$ value. $F$ is spatial scale, taking on values of $2-20$ periods of $5 \mathrm{n} . \mathrm{m}$. Since densities above the $5 \mathrm{n} . \mathrm{m}$. scale are means of densities pooled within larger sampling units, we tested the correlations at larger scales against the underlying $5 \mathrm{n} . \mathrm{m}$. scale (see Heinemann et al. 1989).

The numerical correlation (defined as the rank correlation between seabird numbers and prey densities where both are present) was estimated at the $5 \mathrm{n} . \mathrm{m}$. scale only. Since numerical association may manifest itself only above some threshold in prey density (Piatt 1987; Heinemann et al. 1989), 
we analysed 'low density' and 'high density' patches separately. 'High density' prey patches were selected according to discontinuities in the distribution of prey densities and in such a way that an appropriate number of $5 \mathrm{n} . \mathrm{m}$. periods was obtained for statistical testing.

\section{Results}

\section{Bird densities}

A total of 8,726 birds were seen within the 1,143 10 min. periods, giving a total of 7.6 birds per $\mathrm{km}^{2}$. Brünnich's Guillemots and Common Guillemots were by far the most common alcid species, and totalled $90.8 \%$ of all birds seen. Only $38.4 \%$ of the guillemots seen could be identified to species, but the ratio of those identified showed that Brünnich's Guillemots were by far the most numerous $(88.3 \%)$. Other auks seen were (in decreasing order of abundance): Little Auk Alle alle (5.6\%), Puffin Fratercula arctica (3.1\%), Razorbill Alca torda $(0.1 \%)$ and Black Guillemot Cepphus grylle $(0.06 \%)$. Because of their small number, these four species were left out of the calculations below.

Of the total number of Brünnich's and Common Guillemots seen $(\mathrm{N}=7,919), 61.2 \%$ were seen on water and $38.8 \%$ flying. In the calculations of the correlations between birds and prey only birds seen on the water were considered, since flying birds are not necessarily associated with the habitat and their numbers can not be expected to be closely linked to the presence of food.

\section{Spatial distribution of guillemots and prey}

Both birds and prey showed a clear non-random distribution where low density patches alternated with high density patches along the transect (Fig. 2). Of the 388 five nautical mile periods where we had both bird and prey data, birds were present in $275(70.9 \%)$ periods, prey present in $243(62.6 \%)$ and both birds and prey in 173 out of 275 periods $(62.6 \%)$.

The degree of spatial association of birds and prey varied during the day (Table $1, \chi^{2}=27.2$, $\mathrm{df}=4, \mathrm{P}<0.001)$. It was highest during the day $(1000-1400,75 \%)$ and lowest at night $(0200-0600$, $21 \%)$.

The proportion of birds seen on water (and which were presumably feeding (Table 1)) varied

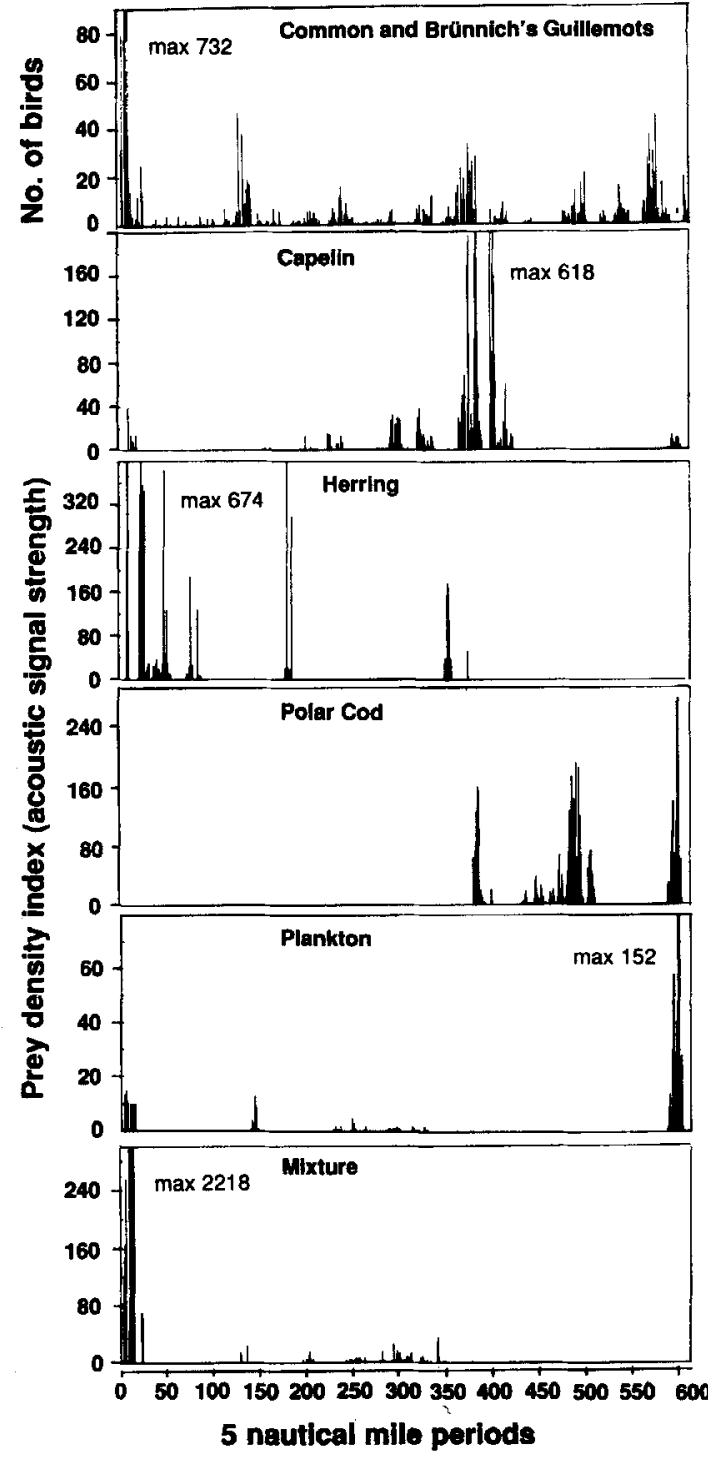

Fig. 2. Number of Common and Brünnich's Guillemots and density of different prey categories along a transect in the southern Barents Sea.

throughout the day and night. The maximum occurred when prey and birds were most closely correlated (1000-1400).

The overall spatial associations of birds and prey irrespective of time of day were low for single prey categories (range from $8 \%$ in herring to $33.8 \%$ for capelin (Table 2)). Between 1000 and $1400 \mathrm{hrs}$., the association of capelin increased to $58.9 \%$, which differed significantly $\left(\chi^{2}=\right.$ 
Table 1. Percentage of Common and Brünnich's Guillemots seen in the southern Barents Sea on water $(\mathrm{N}=$ total number of birds seen) and the percentage of 5 nautical miles with birds that also had prey present $(\mathrm{N}=$ total number of 5 mile blocks with birds within this time period) during 4-h time blocks from $0200-2200$ local time.

\begin{tabular}{lccccc}
\hline Time of day & $0001-0400$ & $0401-0800$ & $0801-1200$ & $1201-1600$ & $1601-2000$ \\
\hline & $(\mathrm{N}=748)$ & $(\mathrm{N}=1,081)$ & $(\mathrm{N}=3,082)$ & $(\mathrm{N}=1,305)$ & $(\mathrm{N}=1,501)$ \\
Birds on water $(\%)$ & 15.6 & 54.0 & 85.9 & 49.8 & 46.3 \\
& $(\mathrm{~N}=19)$ & $(\mathrm{N}=72)$ & $(\mathrm{N}=55)$ & $(\mathrm{N}=64)$ & $(\mathrm{N}=64)$ \\
5 mile periods with & 21.1 & 37.5 & 70.5 & 65.7 & 60.9 \\
birds and prey (\%) & & & & \\
\hline
\end{tabular}

12.4, df $=1, P<0.001$ ) from when all time periods were considered, but the association with other single prey categories remained very low.

The low spatial association between birds and single prey categories is also obvious from Figs. 2 and 3 , since birds were distributed in patches along the whole transect while each prey category was restricted to smaller areas with partly nonoverlapping distributions. Most illustrative are the distributions of the schooling species capelin, herring and polar cod, which overlapped very little spatially. Capelin were most common in the northwestern part of the study area, while herring and polar cod were distributed to the south and east, respectively (Fig. 3).

\section{Overall correlation and spatial scaling}

Since it is obvious from inspection of the data that no single prey category could explain the distributional patterns of birds, we carried out an exploratory analysis of overall correlation between birds and prey first by combining all five prey categories at both depths and then stepwise removing different combinations of prey categories and depths to evaluate combinations where we achieved the highest significant correlation.

At the $5 \mathrm{n} . \mathrm{m}$. scale there was a statistically significant correlation between birds and total prey density at depths $100-200 \mathrm{~m}$ and $10-200 \mathrm{~m}$ (Fig. 4). The coefficients were low $(0.14-0.20)$ but could be increased somewhat $(0.18-0.25)$ by aggregating data on the 10 n.m. scale. Coefficients were not significantly higher at larger scales, suggesting an absence of scale dependent correlation.

The removal of herring from the calculations increased the strength of correlation. At the $5 \mathrm{n} . \mathrm{m}$. scale, correlations ranged from $0.22-0.29$ but were again only signficant at depths 100 $200 \mathrm{~m}$ and $10-200 \mathrm{~m}$. Maximum significant correlation coefficient was achieved at $100-200 \mathrm{~m}$ on a scale of $90 \mathrm{n} . \mathrm{m} .(0.54)$ and at $10-200 \mathrm{~m}$ on a scale of $80 \mathrm{n} . \mathrm{m} .(0.50)$. According to Fig. 4 , there appears to be some upper threshold in the coefficients reached around a scale of $40 \mathrm{n} . \mathrm{m}$.(r-values of about 0.43 ). Above 40 n.m. the r-values fluctuated markedly, although maximum significant correlation coefficients were achieved at 80 and $90 \mathrm{n} . \mathrm{m}$. for depths $100-200 \mathrm{~m}$ and $10-200 \mathrm{~m}$, respectively. The highest correlation was achieved when using the three prey categories capelin/10-100 m, mixture/10-100 m and plankton $/ 10-200 \mathrm{~m}$. These coefficients were significant at all scales, and reached a maximum at 90 n.m. $(r=0.64)$.

Overall correlations between seabird and prey density means at the 'segment' periods (Fig. 5) were strong $(r=0.63)$. This correlation coefficient also differed significantly from the underlying $5 \mathrm{n} . \mathrm{m}$. correlation.

\section{Numerical correlation}

Correlations between birds and prey at the 5 n.m.

Table 2. The presence of different prey categories (\%) in 5 mile periods where birds were present according to different times of day. $\mathrm{N}=$ number of $5 \mathrm{n} . \mathrm{m}$. periods.

\begin{tabular}{lccccccc}
\hline & Capelin & Herring & Polar cod & Plankton & Mixture & Total \\
\hline All times of day & $(\mathrm{N}=275)$ & 33.8 & 8.0 & 15.6 & 12.4 & 17.4 & 62.9 \\
Day time (1001-1400) & $(\mathrm{N}=56)$ & 58.9 & 7.0 & 17.9 & 21.4 & 28.6 & 75.0 \\
\hline
\end{tabular}



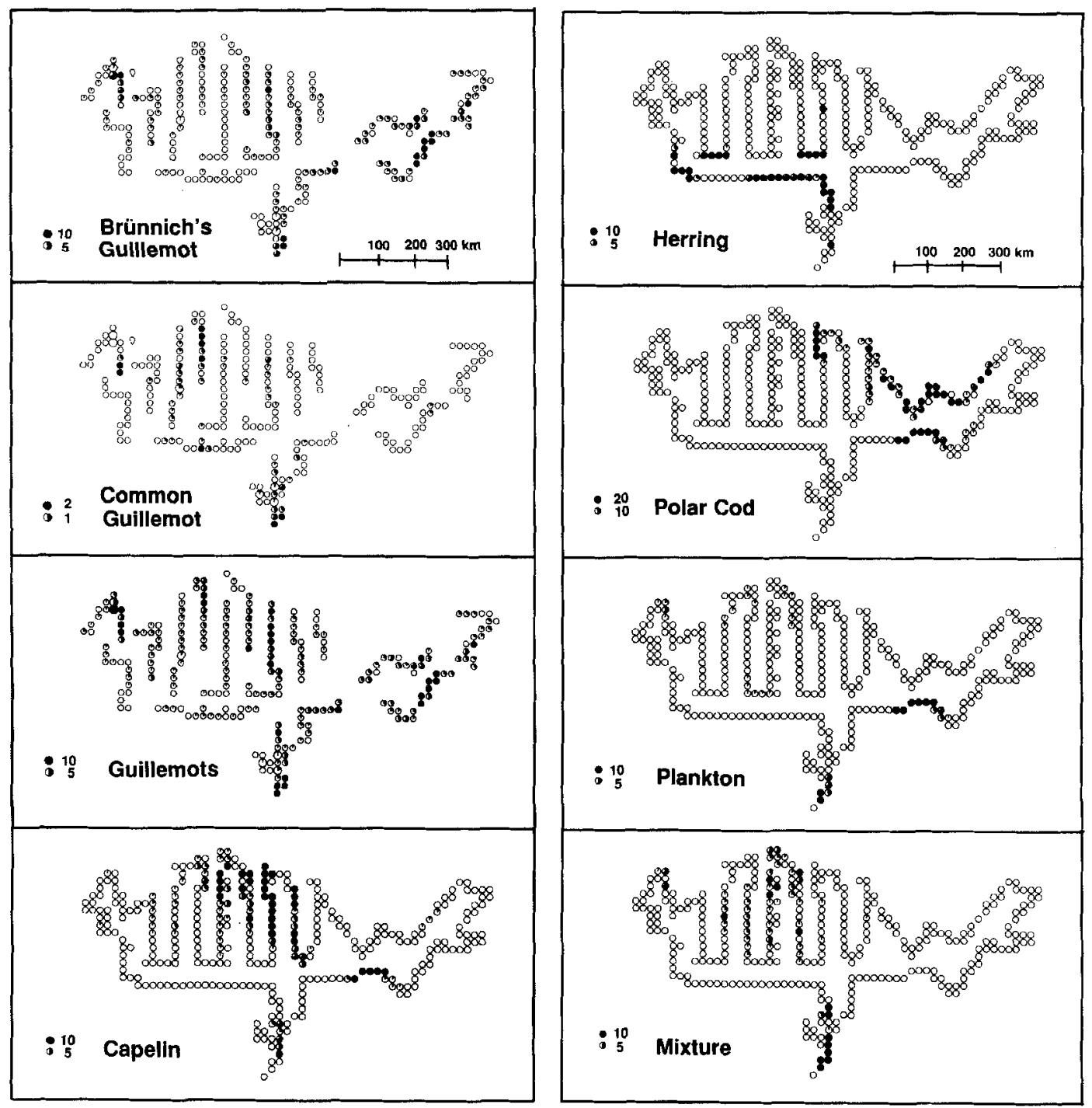

Fig. 3. The distribution of Common and Brünich's Guillemots and different prey categories in the southern Barents Sea. Filled circles indicate number of birds/ $\mathrm{km}^{2}$ or mean acoustic signal strength $/ \mathrm{km}^{2}$ (for different prey categories).

scale when both were present were significant $(r=0.42)$. The correlations were much higher for high density prey patches $(r=0.71)$ than for low density patches $(r=0.35)$, suggesting that numerical concordance between birds and prey may first manifest itself when a threshold is reached (Fig. 6). These high density prey patches covered only $5.6 \%$ of the area studied but included as much as $58.2 \%$ of all birds seen.

\section{Discussion}

\section{Spatial distribution of birds and prey}

The association of birds and prey showed a clear diel pattern, and was highest during day time when the largest number of birds was seen on the water (presumably feeding birds). Accordingly, the time of day (diel feeding rhythm) is an 


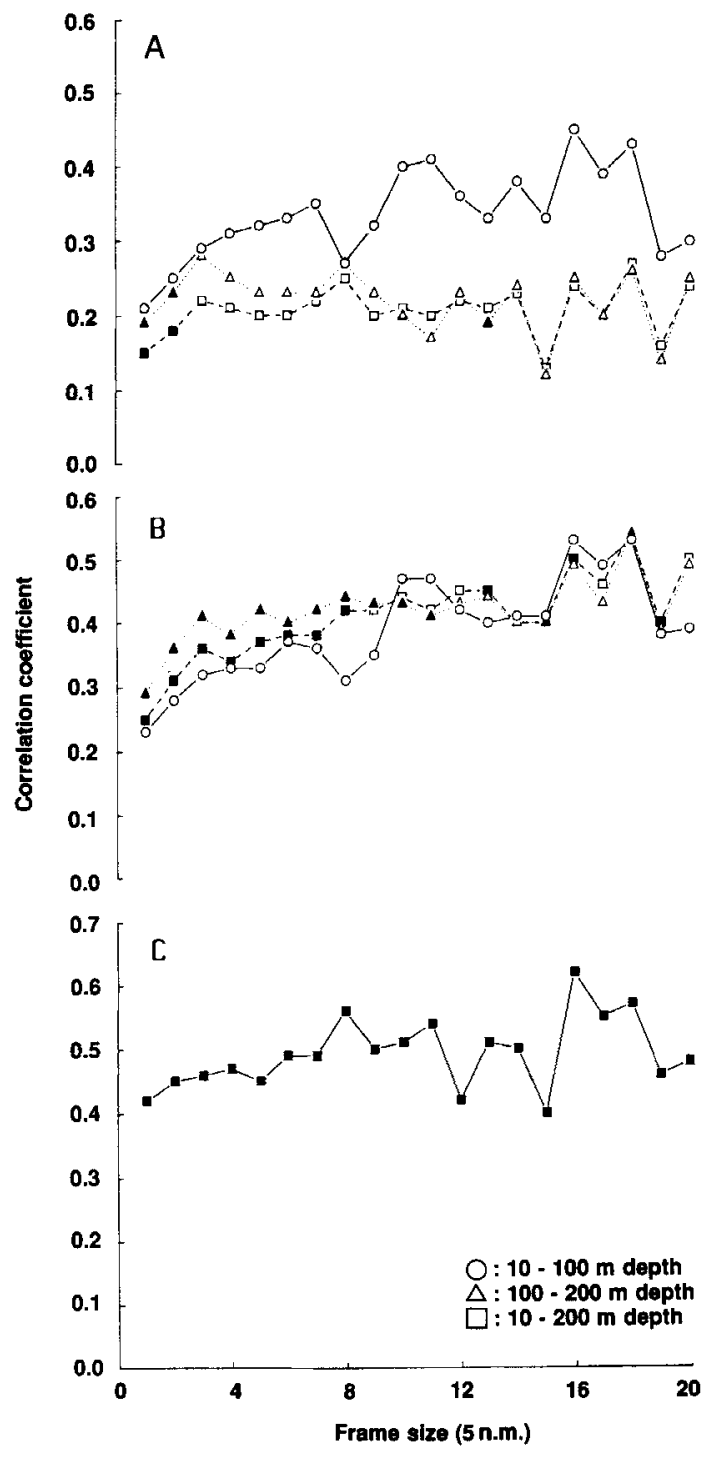

Fig. 4. Correlations between guillemots Uria spp. and prey in the southern Barents Sea at different depths as a function of measurement distance (5 nautical mile periods). A. Guillemots and total prey density. B. Guillemots and prey when herring is removed from the calculations. C. Guillemots and the prey categories which gave the highest correlation coefficients (capelin at depth 10-100 $\mathrm{m}$. plankton at both depths, and mixture at depth $10-100 \mathrm{~m}$ ). Statistical significance is indicated by solid symbols $(\mathrm{p}<0.05)$.

important factor which has to be considered when evaluating the correlations between birds and prey. Birds on the water include both resting and feeding birds (which are difficult to differentiate), while flying birds are presumably searching for food either by looking for other feeding birds or by spotting surface prey, and are therefore expected to be less associated with prey. Woodby (1984), who also addressed this problem in the southeastern Bering Sea, noted a similar diurnal pattern in the number of guillemots seen on water but he did not evaluate the degree of association between birds and prey at different times of the day.

There was no single prey category which alone could explain the distributional patterns of birds. This agrees with recent studies of the diets of seabirds from the Barents Sea where Brünnich's Guillemots may feed heavily on both capelin, cod, and crustacea during the non-breeding season (Erikstad \& Vader 1989; Erikstad in press).

There is less information on the diet of Common Guillemots but they have been shown to prey on capelin close to the breeding colonies during the prelaying season (Erikstad \& Vader 1989 ). From the open sea there is to date no study, but there is a general acceptance that they rely heavily on capelin also at this time of the year (Barrett 1979; Vader et al. in press), a suggestion which is in accordance with diet studies from the breeding colonies in this study area (Furness \& Barrett 1985). Unfortunately we were not able to evaluate the associations between capelin and the two guillemot species separately, as only a small fraction of birds of the two species could be differentiated. However, there is some evidence that Common Guillemots may be more strongly associated with capelin than Brünnich's Guillemots. First, capelin was the single prey species which was most common in areas where birds were located. Secondly, the distribution of the few Common Guillemots identified was similar to the distribution of capelin which covered the northwestern part of the transect system (Fig. 3). Brünnich's Guillemots were distributed throughout the area investigated. In the northwestern part they overlapped with the Common Guillemot but in the eastern part Brünnich's Guillemots were found alone within the range of polar cod but outside the capelin area.

Herring was the only prey category which was less associated with birds than initially expected. At first sight this may seem contradictory since herring is known to have been an important nourishment for both guillemot species during summer in the eastern parts of the Barents Sea (Belopol'skii 1957). However, the herring available in this study (mean length c. $20 \mathrm{~cm}$ with only 


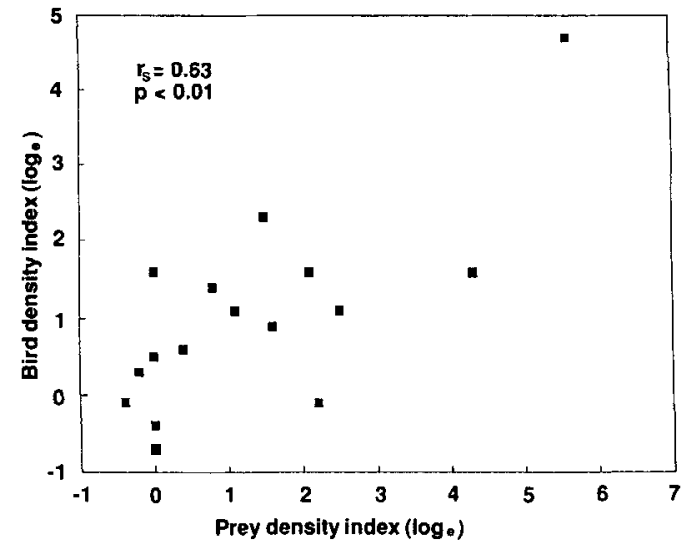

Fig. 5. Overall correlation between mean density of guillemots and prey at the 'segment' intervals.
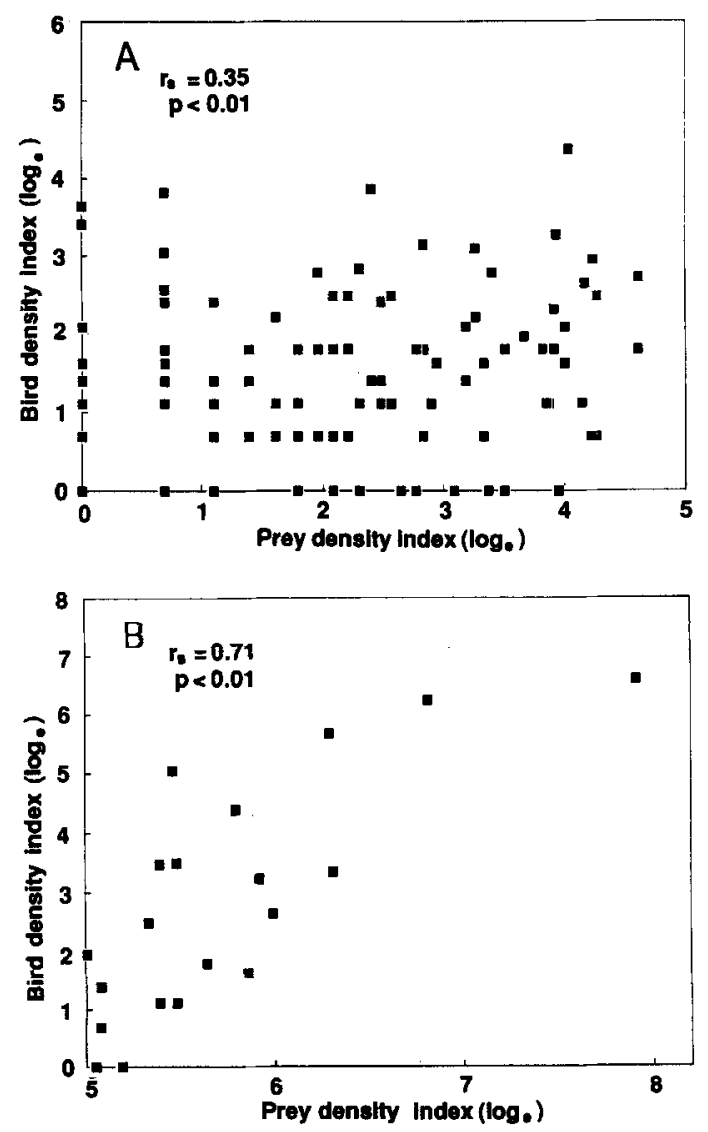

Fig. 6. Numerical correlation (where both birds and prey were present) between guillemots and prey in the southern Barents Sea at low (A) and high (B) density prey patches. a very few specimens less than $18 \mathrm{~cm}$, unpublished data from the Norwegian Fishery Institute) may have been too large for the guillemots to feed on. Herring of $20 \mathrm{~cm}$ length have a body height of c. $45 \mathrm{~mm}$. Although Common Guillemots are able to swallow fish of this size, Swennen \& Duiven (1977) found that they prefer much smaller (c. $12 \mathrm{~cm}$ ) fish. This result agrees with the observed size range of other fish fed upon by the two guillemot species in the Barents Sea. Erikstad \& Vader (1989) showed that Common and Brünnich's Guillemots feed on capelin of c. $15 \mathrm{~cm}$ during the prelaying season, which is also consistent with studies from the breeding season (Furness \& Barrett 1985; Barrett \& Furness unpublished). Brünnich's Guillemots feed on 8 $12 \mathrm{~cm}$ cod and polar cod during winter (Erikstad in press),

The capelin recorded in this study had a mean size of $15 \mathrm{~cm}$ (unpublished data from the Norwegian Fishery Institute), suggesting that most of the capelin available were within the appropriate size range for guillemots. We know nothing about the size range of the other prey categories present in this study.

\section{Spatial scaling and overall correlation}

At the smallest scale of $5 \mathrm{n} . \mathrm{m}$. there was a significant, albeit low, positive correlation between bird and total prey density. The correlation coefficient increased when herring was removed from the calculation. At spatial scales greater than $5 \mathrm{n} . \mathrm{m}$. the correlations increased and reached a maximum at $80 \mathrm{n} . \mathrm{m}$. $(145 \mathrm{~km})$. However, there appears to be some upper threshold in the correlation reached at about $30-40 \mathrm{n} . \mathrm{m}$. $(54 \mathrm{~km})$. The highest correlation coefficient was achieved when using the prey categories capelin $/ 10-100 \mathrm{~m}$, plankton $/ 10-200 \mathrm{~m}$ and mixture $/ 10-100 \mathrm{~m}$. It is difficult to make any reasonable interpretation of this result. Presumably it is accidental and caused by some intercorrelations of different prey categories.

The depth at which different prey categories were distributed had little effect on the strength of the correlation. In fact the coefficient was somewhat higher for the depth range $100-200 \mathrm{~m}$ than for $10-100 \mathrm{~m}$. That birds seem to track prey independent of depth may be a result of several mechanisms. Guillemots can dive to depths greater than $100 \mathrm{~m}$ (Piatt \& Nettleship 1985; Burger \& Simpson 1986) even though they may 
feed in shallower water (Barrett \& Furness unpublished). Moreover, young year classes of important prey categories in the Barents Sea, such as capelin and cod, show diurnal vertical migration patterns and are found near the surface during the day (e.g. Belstad et al. 1975). This pattern is consistent with the diurnal variation in birds seen on the water in this study. To draw firm conclusions about the importance of the depth of prey, a detailed study of patches of feeding birds in relation to prey depth is needed.

The present study is one of four which have documented a positive correlation between bird and prey density (Schneider \& Piatt 1986; Piatt 1987; Heinemann et al. 1989). The results presented here are also consistent with the other three studies in that the degree of correlation was higher at larger spatial scales. Schneider \& Piatt (1986) described three different mechanisms which may cause reduced correlation at a smaller scale: 1) local avoidance of the dense prey patches, 2) differences in locomotory capacities of birds and prey and 3) 'sit and wait predation' by birds within extended aggregations of prey. Local avoidance of dense prey patches seems unlikely in this study, since there was a high numerical correlation (where both birds and prey were present) between bird and prey density. We know less about the other two mechanisms but differences in the locomotory capacity of birds and prey may also be of importance in this study. Capelin, which is presumably the most important prey for guillemots, migrate from the northern Barents Sea to the coast of Norway and Murmansk (Jangaard 1974; Sætre \& Gjøsæter 1975) at the time of year this study was carried out. Rapid swimming by capelin schools may make it difficult for birds to track them, especially at night when they are not feeding (see also Schneider \& Piatt 1986).

Heinemann et al. (1989) mention two other factors which may explain the lower correlation at small scales: 1) Most prey patches are unexploited at any given time and 2) a small number of prey patches are disproportionately important to birds. We know nothing about the exact number of prey and bird patches in this study but at the 5 n.m. scale there is no apparent excess of prey patches (Fig. 2). Such a low number of prey patches in relation to bird patches may be a consequence of the severely reduced stocks of three important fish species in the study area, namely herring, capelin and cod (Hamre 1986,
1988; Bergstad et al. 1987). This reduction in prey abundance has also recently led to dramatic decreases in the breeding populations of both Common and Brünnich's Guillemots in the area (Vader et al. in press).

That some prey patches are more important to birds than others does not seem to be justified in this study. In fact there was a very close positive correlation between the sizes of prey and bird patches above some threshold (numerical concordance), suggesting that birds are very good at detecting prey and presumably also at evaluating the relative value of prey patches when prey availability is low. The results presented by Piatt (1987) are interesting in this context. In a study on Common Guillemots and capelin from Witless Bay, Newfoundland, he found evidence for an upper threshold in prey density. Maximum correlation between guillemots and capelin was achieved at an intermediate density of capelin. Piatt (1987) suggested that the capture rate of prey by birds levelled out at some threshold and that birds could not increase their foraging success further by selecting patches above this level. The general prey density in the Barents Sea was possibly at such a low level that this upper threshold was not reached.

\section{Strength of correlation}

The strength of correlation between prey and pelagic seabird density varies greatly in different studies from very low $(6-8 \%)$ to very high explained variances (above $90 \%$, Schneider \& Piatt 1986; Heinemann et al. 1989). Although few studies have been carried out, there appears to be some general trend in the results obtained, as pointed out by Hunt (this volume). Studies focusing on diurnally foraging alcids and capelin have been more successful in finding positive correlations (Schneider \& Piatt 1986; Piatt 1987) than those focusing on seabirds and krill (Obst 1985; Heinemann et al. 1989). As pointed out by Hunt (this volume), the majority of krill specialists take their prey at night, whereas birds have to be counted during the day. He also mentions the possibility that planktivorous birds are less able to locate the densest prey patches or, alternatively, that they may not need to seek the densest patches if background densities or the frequency of micro-patches of prey at high densities are sufficiently great (Hunt this volume).

When comparing results from different studies, 
the use of different correlation techniques should be taken into account. Schneider \& Piatt (1986), who have found the highest coefficients $(0.88-$ 1.0 ), used the product moment correlation coefficient. In this study we estimated the Spearman rank correlation. Calculating the product moment correlation on our data gives an r-value of 0.86 at the 5 n.m. scale, whereas the Spearman rank correlation at this scale was only 0.23 . However, we felt that the Spearman statistic was more appropriate, since the correlation was driven by a few large patches of birds and prey.

Schneider \& Piatt (1986) observed that the correlation between birds and prey was only intermittent and repeated surveys were necessary for detection of correlations (see also Safina \& Burger 1985, 1988). They found that the correlation of birds and capelin was significant in only 6 out of 12 transects ranging in length from 15 to $30 \mathrm{~km}$. With this in mind, the r-values obtained in this study along one long transect of nearly $6,000 \mathrm{~km}$ are high. The severe reduction of important prey species in the Barents Sea (Hamre 1986, 1988; Røttingen this volume) may have contributed to this result. A strong reduction in populations of prey species may also reduce the number of prey patches and make it more difficult for birds to track prey at sea. This may explain the mass starvation of Common Guillemots in the study area during the winter of 1987 (Vader et al. in press), when the capelin stock was at its lowest level (Hamre 1988). However, such a reduction in the number of prey patches may strengthen the correlations between birds and prey, since the number of prey patches which at any time are unexploited may be low. Hence, it can be hypothesized that correlations between birds and prey should decrease when prey density increases. Both the capelin and herring stocks are slowly recovering in the Barents Sea (Hamre 1988), which gives us the unique opportunity to test this hypothesis by repeating counts along such an extended transect during the years of recovery.

\section{Conclusion and management implications}

Hunt (this volume) mentions three assumptions which are implicit in the hypothesis that predators should aggregate where prey are most abundant: 1) There is a close coupling between prey abundance and prey availability, 2) the predators are good at detecting and evaluating the relative value of prey patches and 3) predators do not deplete prey patches prior to measurement of prey abundance.

All of these assumptions seem to be reasonably well justified in this study. Birds and prey were closely coupled especially during the day, and the high numerical correlation between birds and prey suggests that birds were both effective in locating and evaluating the relative value of prey patches. A high numerical correlation also suggests that the birds had not depleted the prey patches severely before measurement. Accordingly, at a scale of 30-40 n.m. the distribution of birds could be predicted fairly well, using data on prey distribution and abundance. In fact about $60 \%$ of all birds, which were located within only $5 \%$ of the study area, could be closely predicted by extremely high values of prey abundance.

Predicting the distributional patterns of pelagic seabirds using standard acoustic prey density estimates has important management implications in areas such as the Barents Sea, where pelagic fish species are heavily exploited and where both the distribution and density of fish species are closely monitored. However, before drawing any final conclusion about the usefulness of standard prey data in predicting seabird abundance, further studies are needed. Repeated surveys should be carried out in years when prey density increases (see discussion above) and further studies should also aim at estimating the predictability of prey patches within larger areas of the ocean.

Acknowledgements. - We are grateful for the help and cooperation of the captain, crew and scientists on board $R / V$ 'Eldjarn'. We also thank V. Bakken, K. O. Jacobsen and I. Johnsen for help with the bird observations, H. M. Iversen for programming and the Fisheries Research Institute in Bergen for letting us use their acoustic data on different fish species. David Schneider and Rob Barrett kindly made comments on an earlier draft of this paper and Rob Barrett also corrected the English. This study was part of a larger project (FOBO), studying the pelagic distribution of seabirds and their prey in the Barents sea. The study was financed by the Norwegian Research Council for Science and the Humanities and the oil companies operating in the Barents Sea area (OKN).

\section{References}

Barrett, R. T. 1979: Small oil spill kills 10-20,000 seabirds in northern Norway. Mar. Poll. Bull. 10, 253-255.

Belopol'skii, L. O. 1957: Ecology of sea colony birds of the Barents Sea (Engl. transl. 1961, IPST, Jerusalem). 
Belstad, A. K., Nakken, O. \& Smestad, O. M. 1975: Investigations on diel vertical migration of 0 -group fish in the Barents Sea. FiskDir. Skr. Ser. HavUnders. 16, 229-244.

Bcrgstad, O. A., Jørgensen, T. \& Dragesund, O. 1987: Life history and ecology of the gadoid resources of the Barents Sea. J. Fish. Res. 5, 119-161.

Burger, A. E. \& Simpson, M. 1986: Diving depths of Atlantic Puffins and Common Murres. Auk 103, 828-830.

Emery, K. O., Milliman, J. D. \& Uchupi, E. 1973: Physical properties and suspended matter of surface waters in the southeastern Atlantic Ocean. J. sedim. Petrol. 43, 822-837.

Erikstad, K. E. in press: Winter diets of 4 seabird species in the Barents Sea after a crash in the capelin stock. Polar Biol.

Erikstad, K. E., Bustnes, J. O.\& Jacobsen, O. 1988: Duration of ship-following by Kittiwakes Rissa tridactyla in the Barents Sea. Polar Research 6, 191-194.

Erikstad, K. E. \& Vader, W. 1989: Capelin selection by Common and Brünnich's Guillemots during the prelaying season. Ornis Scand. 20, 151-155.

Furness, R. W. \& Barrett, R. T. 1985: The food requirements and ecological relationships of a seabird community in North Norway. Ornis Scand, 16, 305-313.

Hamre, J. 1986: Bestands- og forvaltningspolitikk for lodde og sild i 1979 og 1980-ărene. Seminar om Barentshavets ressurser. Rapp. Norges Fiskarlag/Fiskeridir. Havfors. kningsinstitutt, 72-93.

Hamre, J. 1988: Some aspects of the interrelation between the Herring in the Norwegian Sea and the stocks of Capelin and Cod in the Barents Sea. Unpubl. ICES paper C.M. 1988/ H:42. 15 pp.

Heinemann, D., Hunt, G. L., Jr. \& Everson, I. 1989: The distributions of marine avian predators and their prey, Euphausia superba, in the Branfield Strait and southern Drake Passage, Antarctica. Mar. Ecol. Prog. Ser. 58, 3-16.

Hulsman, K. 1981: Width of gape as determinants of size of prey eaten by terns. Emu $81,29-32$.

Hunt, G. L., Jr. 1990: The pelagic distribution of marine birds in a heterogencous environment. Polar Research 8, 4354

Hunt, G. L., Jr. \& Schneider, D. C. 1987: Scalc-dependent processes in physical and biological environment of marine birds. Pp. 7-41 in Croxall, J. P. (ed.): Seabirds: feeding biology and role in marine ecosystems. Cambridge University Press, Cambridge.

Jangaard, P. M. 1974: The capelin (Mallotus villosus): biology, distribution, exploitation, utilization and composition. Bull. Fish. Res. Bd. Can. 186, 1-70.

Johannesson, K. A. \& Mitson, R. B. 1983: Fisheries acoustics. A practical manual for aquatic biomass estimation. FAO Fish. Tech. Pap. 240. 249 pp.

Loeng, H. 1989: Ecological features of the Barents Sea. Pp.
327-365 in Rey, L. \& Alexander, V. (eds.): Proc. 6th conf. comité arct. int. May 1985.

Midttun, L. 1985: Formation of dense bottom water in the Barents Sed. Deep Sea Research 32, 1233-1244.

Midttun, L. 1990: Surface temperatures of the Barents Sea. Polar Research 8, 11-16.

Obst, B. S. 1985: Densities of Antarctic seabirds at sea and the presence of the Krill Euphausia superba. Auk 102, 540-549.

Piatt, J. F. 1987: Behavioural ecology of Common Murre and Atlantic Puffin predation on capelin; implications for population ecology. Ph.D. thesis, Department of Biology, Memorial University of Newfoundland, St. John's.

Piatt, J. F. \& Nettleship, D. N. 1985: Diving depths of four alcids. Auk 102; 293-297.

Pingree, R. D., Pugh, P. R., Holligan, P. M. \& Foster, G. R. 1975: Summer phytoplankton blooms and red tides along tidal fronts in the eastern Barents Sea. J. Geophys. Res. 83, 4659-4667.

Røttingen, I. 1990: Changes in the distribution and abundance of Norwegian spring spawning herring and Barents Sea capelin. Polar Research 8, 33-42.

Safina, C. \& Burger, J. 1985: Common tern foraging. Seasonal trends in prey fish densities and competition with bluefish. Ecology 66, 1457-1463.

Safina, C. \& Burger, J. 1988: Ecological dynamics among prey fish, bluefish, and foraging Common Terns in an Allantic coastal system. In Burger, J. (ed.): Seabirds and other marine vertebrates. Columbia University Press, New York.

Schneider, D. C. 1990: Seabirds and fronts: a brief overview. Polar Research 8, 17-21.

Schneider, D. C. \& Duffy, D. C. 1985: Scalc-dependent variability in seabird abundance. Mar. Ecol. Prog. Ser. 25, 211218.

Schneider, D. C. \& Piatt, J, 1986: Scale-dependent correlation of seabirds with schooling fish in a coastal ecosystem. Mar. Ecol. Prog. Ser. 32, 237-246.

Swennen, C. \& Duiven, P. 1977: Size of food objects of thrce fish-eating scabird species: Uria aalge, Alca torda, and Fratercula arctica (Aves, Alcidae). Neth. J. Sea Res. 11, 92-98.

Sætre, R. \& Gjøsæter, J. 1975: Ecological investigations on the spawning grounds of the Barents Sea capelin. FiskDir. $\$ k$ r. Ser. HavUnders. 16, 203-227.

Tasker, M. L., Hope Jones, P., Dixon, T. \& Blakc, B. F. 1984 Counting scabirds at sea from ships: A review of methods and a suggestion for a standard approach. Auk 101,567-577.

Vader, W., Barrett, R. T., Erikstad, K. E. \& Strann, K.-B. in press: Differential responses of Common and Thick-billed Murres Uria spp. to a crash in the capelin stock in the southern Barents Sea. Studies in Avian Biol.

Woodby, D. A. 1984: The April distribution of murres and prey patches in the Bering Sea. Limnol. Oceanogr. 29, 181-188. 
